\title{
Russian Roulette with Rotterdam Convention
}

\author{
Oladele A. Ogunseitan
}

Opinion: For Your Consideration

Always interested in hearing the thoughts of our readers, JOM offers For Your Consideration as a forum for individual opinions. On this page, we encourage thoughtful discourse on topics pertaining to JOM coverage areas.

Opinions expressed are the author's and not necessarily those of TMS or the editorial staff.

\section{We want to hear from}

you! Find out how to

submit your opinion to

JOM at http://www.tms

.org/pubs/journals/JOM

/authorTypesofPapers

.aspx
In his treatise on natural history, Pliny the Elder described the invention of a woven napkin material that is indestructible by fire, which he entitled asbestinon. ${ }^{1}$ The extraordinary qualities of asbestos fibers made them indispensable for numerous domestic and industrial products and processes. However, evidence increasingly accumulated about adverse health effects of asbestos. Akin to compulsively pulling the trigger on a gun loaded with a single rare bullet aimed at the chest, 125 million people are regularly exposed to asbestos fibers, and each year, luck runs out for 107,000 of these people. The outcome for the unlucky is death by mesothelioma among other asbestoslinked preventable diseases. ${ }^{2}$ Eradication of asbestos-related chronic diseases may hinge on banning the mining and use of asbestos fibers in consumer products. Such a ban will require complete cooperation of all nations to adopt binding regulatory policies and the compliance of private corporations with such international decisions.

The United Nations' Rotterdam Convention (RC) provides a nearly perfect framework for advancing toward a mesothelioma-free world. The RC was designed to "promote shared responsibility and cooperative efforts among Parties in the international trade of certain hazardous chemicals in order to protect human health and the environment from potential harm." ${ }^{\prime 3}$ To bridge some of the translational science gaps between countries with robust research programs and countries with great needs in disease prevention, the RC emphasizes informed consent, and aims to facilitate information exchange about hazardous chemicals and materials characteristics, thereby supporting national decision-making processes on their production, importation, and exportation (Figure 1).

Parties to the RC make binding decisions through unanimous consent during biannual conferences. Although desirable for some types of international governance, the requirement for unanimous consent has proven to be a peculiar weakness of the RC. At 3:45 a.m. on 16 May 2015, the meetings of the Conference of Parties to the Basel, Rotterdam and Stockholm Conventions ended with much trumpeted successes toward protecting people all over the world from the adverse health impacts of toxic chemicals. But one major failure largely overshadowed the successes - seven countries, led by Russian Federation and including Cuba, India, Kazakhstan, Kyrgyzstan, Pakistan, and Zimbabwe voiced informal opposition to the adoption of a formal recommendation that chrysotile, the serpentine form of asbestos (CAS No. 12001-29-5), should become subject to the prior informed consent procedure by its inclusion in Annex-III of the RC. ${ }^{5}$

Despite moving testimony from ailing victims of asbestosis and vocal support from most of the 154 Parties to the RC, Russian Federation, Kazakhstan, Kyrgyzstan, and Zimbabwe confirmed their opposition at the final plenary session to shoot down the chrysotile recommendation. The 2015 conference is the fifth time that a few countries will have blocked the inclusion of chrysotile in Annex-III of the RC. Delegates of opposing countries usually give three reasons for their staunch position. First, that there are no cost-effective alternatives for chrysotile in the building, construction, 
automobile, and chloralkali-based industries. Second, that there remains considerable uncertainty about the causal link between chrysotile exposure and lung disease. And third, that a complete ban will increase unemployment and other economic burdens for countries that currently mine and use asbestos.

Materials scientists should be most concerned about the argument that there are no health risks or otherwise suitable alternatives to newer formulations of chrysotile, which are highdensity materials with reduced release of loose fibers.Ultimately, all materials deteriorate, and human exposure to toxic fibers remains a threat throughout the complete life cycle of products manufactured with chrysotile. ${ }^{6}$ Numerous materials have

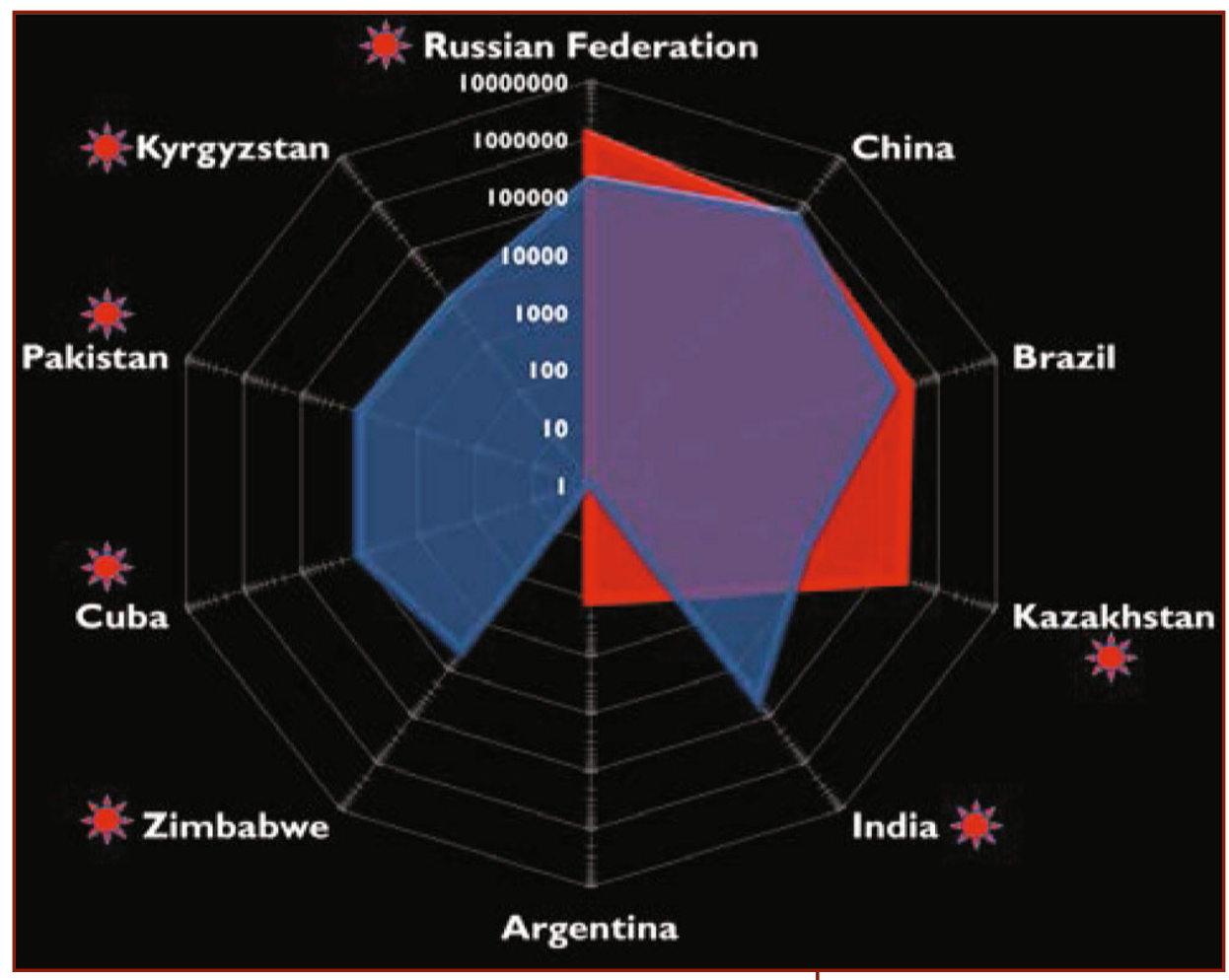
been used or suggested as replacements for asbestos in various products, but without rigorously transparent alternative assessments, it is impossible to conclude that these are without risks. ${ }^{7}$ Many countries have completely banned asbestos without apparent detrimental consequences. A strong binding international regulatory policy on informed consent to discourage international trade of all asbestos fibers will stimulate research to discover evidently better, cheaper, and safer alternatives.

\section{References}

1. J. Bostock and H.T. Riley, The Natural History of Pliny, Vol. IV (London: Henry G. Bohn, 1856), p. 136.

2. O.A. Ogunseitan, Bulletin of the World Health Organization 93, 359 (2015).

3. Rotterdam Convention on the Prior Informed

Consent Procedure for Certain Hazardous Chemicals and Pesticides in International Trade; http://www.pic.int.

4. U.S. Geological Survey, Asbestos Statistics and Information; http://minerals.usgs.gov/minerals/pubs/ commodity/asbestos.

5.Rotterdam Convention, Chemical Review Committee, Chrysotile asbestos; http://www.pic.int/ TheConvention/Chemicals/RecommendedtoCOP/ Chrysotileasbestos/tabid/1186/language/en-US/ Default.aspx.

6. A. Ogunseitan and J.M. Schoenung, MRS Bull. 37, 356 (2012).

7.World Health Organization, Chrysotile Asbestos, (Geneva:WHO, 2014); http://www.who.int/ipcs/ assessment/public_health/chrysotile_asbestos_ summary.pdf.

Oladele A. Ogunseitan is with the Program in Public Health and School of Social Ecology, University of California, Irvine, CA 92697; email Oladele.Ogunseitan@uci.edu.
Figure 1. Seven countries (starred) opposed international informed consent regarding chrysotile, among the world's remaining producers (red plane) and consumers (blue plane) of asbestos (in metric tons).

All information derived from U.S. Geological Survey ${ }^{4}$ and the Rotterdam Convention. ${ }^{5}$ 